\title{
A BF SUBTYPE "Fb1" IS A MARKER GENE OF SOME MONGOLOID POPULATIONS
}

\author{
Koichi Suzuki, Shinya Mutoh, G. Cey-Bert, \\ Shigenori Iro, and Hideo Matsumoto \\ Department of Legal Medicine, Osaka Medical College, \\ 2-7 Daigakumachi, Takatsuki, Osaka 569, Japan
}

\begin{abstract}
Summary A factor B subtype, BF*Fb1, was first detected in Japanese by using isoelectric focusing or agarose gel electrophoresis in Tris/glycine/ Veronal buffer. Our previous studies suggested that $\mathrm{BF} * \mathrm{Fbl}$ may be characteristic of some of Mongoloid populations. To investigate further distribution of $\mathrm{BF}^{*} \mathrm{Fb} 1$, samples randomly collected from Japanese in Yonaguni island of Japan and Cambodian were tested. BF* Fbl was not observed in a Cambodian population whereas in a Japanese population of Yonaguni island, $\mathrm{BF} * \mathrm{Fb} 1$ occurred at a frequency five times as high as those in main islands of Japan. In paternity cases, a Korean family with three offsprings was shown to transmit $\mathrm{BF}{ }^{*} \mathrm{Fb} 1$ from the accused man to one of the offsprings. These data strongly indicate that $\mathrm{BF}^{*} \mathrm{Fbl}$ is a marker gene for some of Mongoloid populations.
\end{abstract}

Key Words factor B (BF), Mongoloid, polymorphism

\section{INTRODUCTION}

Factor B (BF) is a single-chain glycoprotein which establish its initial contact with $\mathrm{C} 3 \mathrm{~b}$ through its $\mathrm{N}$-terminal fragment, $\mathrm{Ba}$, during formation of the $\mathrm{C} 3$ convertase in alternative pathway for complement activation (for review see MüllerEberhard, 1988). The genetic locus of BF is structurally linked to the major histocompatibility complex (MHC) with other complement loci coding for $\mathrm{C} 2, \mathrm{C} 4 \mathrm{~A}$, and C4B and two loci for 21-hydroxylase A (210HA) and B (21OHB) (Carroll et al., 1984, 1985; White et al., 1985). Its genetic polymorphism has been extensively investigated on various populations since the first report of Alper et al. (1972) by using immunofixation agarose gel electrophoresis.

Isoelectric focusing (IEF) technique has provided further possibility to subdivide a single allotype determined by conventional electrophoresis into two subtypes and has also contributed to BF typing (for review see Geserick and Patzelt,

Received September 25, 1989; revised version received December 25, 1989; Accepted December 26,1989 . 
1988). Four sets of subtype have been recognized for each of the two common alleles, $\mathrm{BF}^{*} \mathrm{~F}$ and $\mathrm{BF} * \mathrm{~S}$, as follows: $\mathrm{FA}\left(=\mathrm{F}^{\prime}, \mathrm{Fb}\right)$ and $\mathrm{FB}\left(=\mathrm{F}^{\prime \prime}, \mathrm{Fa}\right)$ (Teng and Tan, 1982; Geserick et al., 1983; Abbal et al., 1985; Nagai et al., 1986; Segurado and Arnaiz-Villena, 1989), SA and SB (David et al., 1983), Sb (Weidinger et al., 1984), and Fbl (Nakamura et al., 1987; Suzuki et al., 1987a, b; FB in Nishimukai et al., 1988). It is reported that the SA-SB subtype set may be misinterpretation resulting from ambiguous banding patterns due to spontaneous BF conversion during sample collection and/or sample storage (Segurado and Arnaiz-Villena, 1989). We have reported the $\mathrm{Fbl}$ subtype by using agarose gel electrophoresis and have shown through conversion analysis that the subtypic polymorphism resides in the Ba fragment (Suzuki et al., 1987a). The Fbl allele occurs at a polymorphic frequency exclusively in Japanese and Chinese among Asian populations thus far studied, and shows a firm association with $\mathrm{C} 2 * \mathrm{C}, \mathrm{C} 4 \mathrm{~A} * 3$, and $\mathrm{C} 4 \mathrm{~B} * 2$, thus forming a complotype "Fb1C32" in Japanese (Suzuki et al., 1987a). In this paper, we present further data on BF polymorphism in two Mongoloid populations and discuss the distribution of the major two alleles and the $\mathrm{BF}^{*} \mathrm{Fbl}$ allele.

\section{MATERIALS AND METHODS}

Samples. EDTA-plasma samples were collected from 99 randomly selected unrelated individuals living in Yonaguni island and sera from 177 Cambodians. Blood samples were also obtained from a Korean family living in Japan tested for paternity. Yonaguni island lies in the most west end of the Yaeyama islands belonging to Okinawa prefecture and lies off the east coast of Taiwan at a distance of $74 \mathrm{~km}$.

Agarose gel electrophoresis ( $A G E$ ). $0.8 \%$ agarose gel was melted with threefold diluted Tris/glycine/Veronal buffer (TGVB, $186 \mathrm{~mm}$ Tris/530 mm glycine/ 31 mM disodium barbiturate/ $5.6 \mathrm{~mm}$ barbital $\mathrm{pH} 8.8$ described by O'Neill et al., 1978) containing $5 \mathrm{~mm} \mathrm{Na}_{2}$ EDTA and poured into gel-casting cassette (gel size, $120 \times$ $250 \times 1 \mathrm{~mm}$ ). Samples were applied $2.5 \mathrm{~cm}$ from the cathodal end by the aid of an application foil and electrophoresed at $20 \mathrm{~V} / \mathrm{cm}$ on a cooling block kept at $4{ }^{\circ} \mathrm{C}$ until $\mathrm{HbA}$ marker migrated about $6 \mathrm{~cm}$. BF bands were in situ precipitated by appropriately diluted polyclonal goat anti-BF serum (Atlantic antibodies, Scarborough, Me., U.S.A.).

Zymosan treatment of serum samples. Serum samples of BF S, BF FS, BF $\mathrm{Fb} 1 \mathrm{~S}$, and BF F obtained in paternity cases were treated with zymosan A (Sigma, St. Louis, Mo., U.S.A.) at a ratio of $25 \mathrm{mg}$ zymosan to $1 \mathrm{ml}$ serum at $37^{\circ} \mathrm{C}$ for 15 hr (Raum et al., 1984). Treated samples were subjected to same electrophoretic procedures described above.

Protein staining. Immunoprecipitated BF bands were visualized by usual Coomassie Brilliant Blue R-250 staining after washing overnight in saline.

C4 allotyping. $\mathrm{C} 4$ allotype was determined only for Yonaguni population according to the method described by Sim and Cross (1986). Cambodian samples 
were not able to be typed owing to deterioration during sample collection and storage.

C2 allotyping. C2 allotype was determined by the technique described elsewhere (Suzuki et al., 1986).

\section{RESULTS AND DISCUSSION}

Table 1 shows the distribution of BF phenotypes and allele frequencies in a Japanese population of Yonaguni island of Japan and a Cambodian population. Besides two common alleles, $\mathrm{BF}^{*} \mathrm{~F}$ and $\mathrm{BF}^{*} \mathrm{~S}$, only $\mathrm{BF}^{*} \mathrm{Fb} 1$ was detected in a Japanese population of Yonaguni island but neither $\mathrm{BF}^{*} \mathrm{Fb} 1$ nor rare alleles were observed in a Cambodian population. Interestingly, $\mathrm{BF}^{*} \mathrm{Fbl}$ occurred in a Japanese population of Yonaguni island at a frequency (0.0758) five times as high as in those of main islands of Japan where the frequency was reported to be $0.0154-0.0215$ (Nakamura et al., 1987; Suzuki et al., 1987a; Nishimukai et al., 1988). The observed numbers of each phenotype gave a good fit with the expected ones calculated by assuming Hardy-Weinberg equilibrium for each population. The electrophoretic patterns of native BF and of zymosan-treated BF are presented in Fig. 1. BF Fb1 migrated a little slower than BF F on agarose gel electrophoresis using TGVB. Electrophoretic variation of $\mathrm{BF} F \mathrm{~F} 1$ resided in the $\mathrm{Ba}$ fragment, which migrated between that of BF F and BF S. Although we have no population data on the distribution of $\mathrm{BF}^{*} \mathrm{Fb} 1$, fortunately we found in disputed paternity cases a Korean family in which $\mathrm{BF}^{*} \mathrm{Fb} 1$ segregated from the accused man (not excluded) to one of three offsprings (Fig. 2). $\quad \mathrm{BF}^{*} \mathrm{Fbl}$ in this family was found to segregate together with $\mathrm{C} 2 * \mathrm{C}, \mathrm{C} 4 * \mathrm{~A} 3$, and $\mathrm{C} 4 \mathrm{~B} * 2$.

The BF allele frequencies among 19 Mongoloid populations were summarized in Table 2 with the data of this study. In Mongoloid populations, only two common

Table 1. Phenotypes distribution and allele frequencies.

\begin{tabular}{lrrrr}
\hline & \multicolumn{2}{c}{ Cambodian } & \multicolumn{2}{c}{$\begin{array}{c}\text { Japanese } \\
\text { (Yonaguni island) }\end{array}$} \\
& No. obs. & No. exp. & No. obs. & No. exp. \\
\hline S & 132 & 132.25 & 60 & 62.24 \\
FS & 42 & 41.49 & 24 & 20.61 \\
F & 3 & 3.25 & 1 & 1.71 \\
Fb1S & 0 & 0 & 13 & 11.90 \\
Fb1 & 0 & 0 & 1 & 0.57 \\
Total & 177 & 176.99 & 99 & 97.03 \\
\hline BF*S & 0.8644 & & 0.7929 & \\
BF*F & 0.1356 & & 0.1313 & \\
BF*Fb1 & 0 & & 0.0758 & \\
\hline
\end{tabular}

$\chi^{2}=0.026,1$ d. f., $0.075<\mathrm{p}<0.9 . \chi^{2}=3.329,2$ d. f., $0.1<\mathrm{p}<0.25$. 

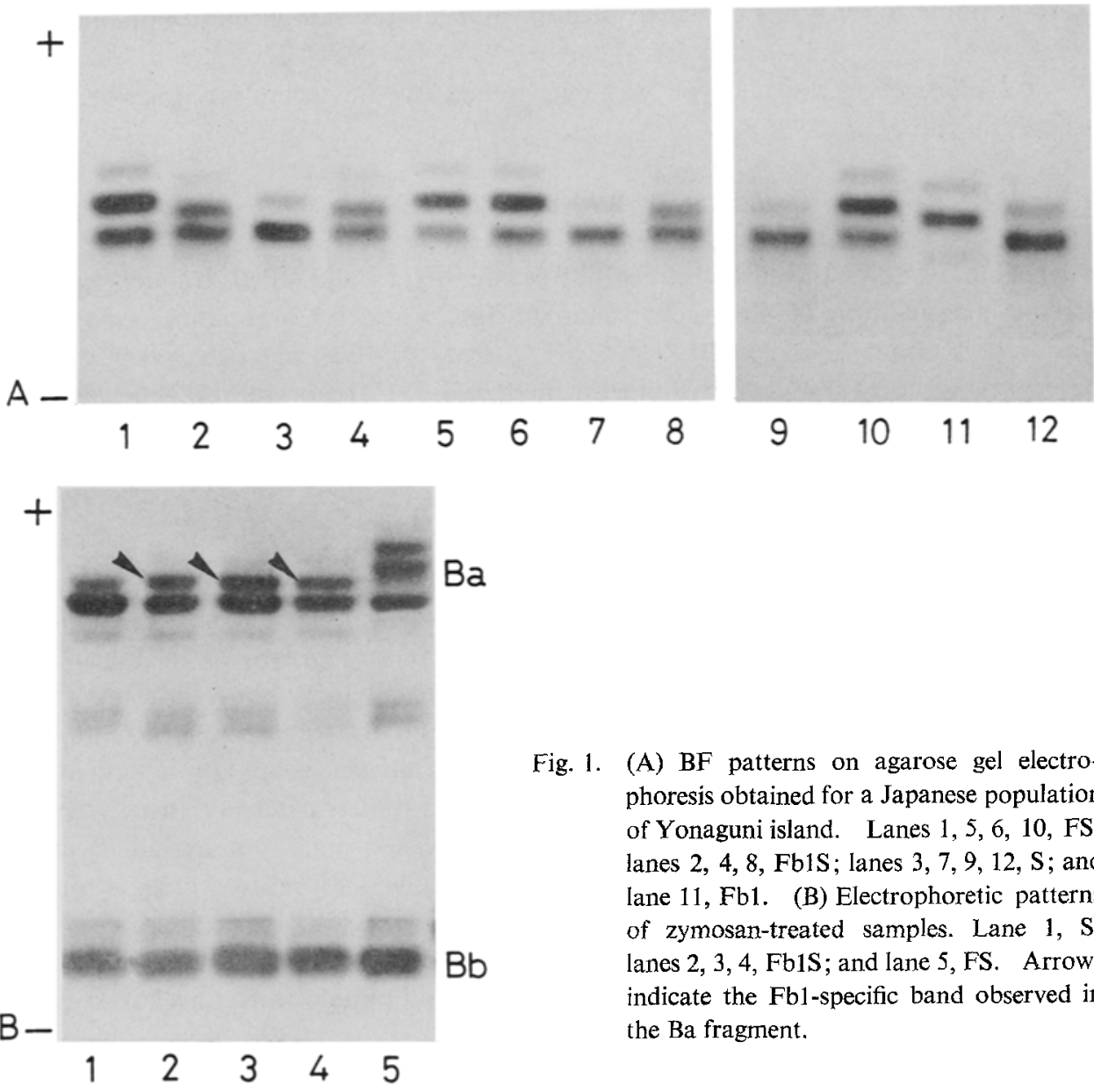

Fig. 1. (A) BF patterns on agarose gel electrophoresis obtained for a Japanese population of Yonaguni island. Lanes 1, 5, 6, 10, FS; lanes 2, 4, 8, Fb1S; lanes $3,7,9,12, \mathrm{~S}$; and lane 11, Fb1. (B) Electrophoretic patterns of zymosan-treated samples. Lane 1, S; lanes 2, 3, 4, Fb1S; and lane 5, FS. Arrows indicate the Fb1-specific band observed in the $\mathrm{Ba}$ fragment.

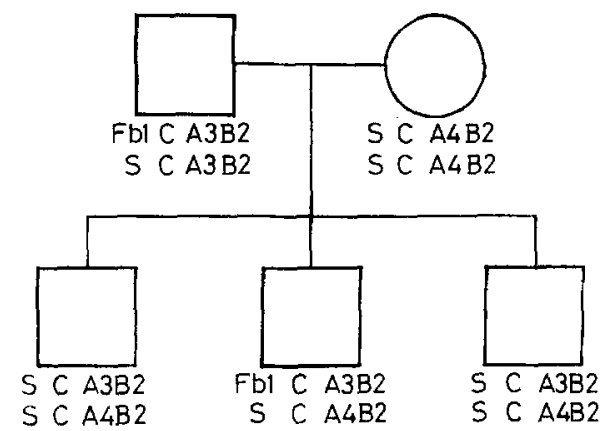

Fig. 2. Pedigree of a Korean family transmitting $B F^{*} F b 1$. In this case the accused man was not excluded by using conventional polymorphic traits ( 7 blood groups, 11 blood cell enzymes, and 15 plasma proteins). Probability for paternity was estimated at $99.999 \%$. 
Table 2. Distribution of $\mathrm{BF}$ alleles among various Mongoloid populations.

\begin{tabular}{|c|c|c|c|c|c|c|c|c|}
\hline Population & Residence & No & $\mathrm{BF}^{*} \mathrm{~F}$ & $\mathrm{BF} * \mathrm{~S}$ & $\mathrm{~F} / \mathrm{S}$ & BF*RARE & $\mathrm{BF} * \mathrm{Fbl}$ & Authors ${ }^{\mathrm{c}}$ \\
\hline \multirow[t]{4}{*}{ Chinese } & Shanghai & 200 & 0.1275 & 0.8700 & 0.15 & S07 & n.t. $b$ & (1) \\
\hline & Guangzhou & 259 & 0.1197 & 0.8668 & 0.14 & S07, SG1, FG2 & n.t. & $(2)$ \\
\hline & Singapore & 55 & 0.1000 & 0.9000 & 0.11 & 0 & n.t. & (3) \\
\hline & Bangkok & 48 & 0.0833 & 0.8890 & 0.10 & F025B, S03, S045 & 0.01 & (4) \\
\hline Korean & Seoul & 220 & 0.2250 & 0.7750 & 0.29 & 0 & n.t. & (5) \\
\hline \multirow[t]{2}{*}{ Filipinos } & Manila & 46 & 0.2830 & 0.7170 & 0.39 & 0 & n.t. & (3) \\
\hline & Manila & 74 & 0.2973 & 0.7027 & 0.42 & 0 & 0 & (4) \\
\hline \multirow[t]{3}{*}{ Thailander } & Bangkok & 184 & 0.0980 & 0.9020 & 0.11 & 0 & n.t. & (6) \\
\hline & Bangkok & 45 & 0.1110 & 0.8890 & 0.12 & 0 & n.t. & (3) \\
\hline & Bangkok & 72 & 0.1528 & 0.8472 & 0.18 & 0 & 0 & (4) \\
\hline Cambodian & n.i. ${ }^{a}$ & 177 & 0.1356 & 0.8644 & 0.16 & 0 & 0 & (7) \\
\hline \multirow[t]{8}{*}{ Japanese } & Nara & 360 & 0.1760 & 0.8240 & 0.21 & 0 & n.t. & (8) \\
\hline & Tokyo & 487 & 0.1980 & 0.8010 & 0.25 & F075 & n.t. & (9) \\
\hline & Western Japan & 534 & 0.1870 & 0.8120 & 0.23 & F075 & n.t. & (10) \\
\hline & Tokyo & 326 & 0.1825 & 0.7945 & 0.26 & F075 & 0.0215 & (11) \\
\hline & Osaka & 325 & 0.1492 & 0.8339 & 0.20 & F075 & 0.0154 & $(12)$ \\
\hline & Wakayama & 53 & 0.1510 & 0.8400 & 0.18 & F065 & n.t. & (3) \\
\hline & Western Japan & 213 & 0.1408 & 0.8404 & 0.19 & F075 & 0.0164 & (13) \\
\hline & Yonaguni & 99 & 0.1313 & 0.7929 & 0.26 & 0 & 0.0758 & (7) \\
\hline
\end{tabular}

a n.i., no information; b n.t., not tested; F+Fb1 was estimated for the calculation of $\mathrm{F} / \mathrm{S}$ ratio. c (1) Zhao 1983, (2) Luo et al. 1987, (3) Miyano et al. 1986, (4) Suzuki et al. 1987b, (5) Park et al. 1985, (6) Greiner et al. 1980, (7) This study, (8) Horai 1976, (9) Tokunaga et al. 1982, (10) Nishimukai 1982, (11) Nakamura et al. 1987, (12) Suzuki et al. 1987a, (13) Nishimukai et al. 1988.

alleles, $\mathrm{BF}^{*} \mathrm{~F}$ and $\mathrm{BF}^{*} \mathrm{~S}$, were detected with some other rare variants as compared with Caucasoid and Negloid populations in which two minor common alleles, $\mathrm{BF}^{*} \mathrm{~F} 1$ and $\mathrm{BF}{ }^{*} \mathrm{~S} 07$, were observed in addition to the two common alleles. A1though a little information is available on the distribution of $\mathrm{BF}^{*} \mathrm{Fb} 1$ among Mongoloid populations, $\mathrm{BF} * \mathrm{Fbl}$ occurs at least in Japanese, in Chinese and probably in Korean at polymorphic frequencies. $\mathrm{BF}^{*} \mathrm{Fb} 1$ is able to be detected by using agarose gel electrophoresis with TGVB in place of the standard barbital buffer for BF typing and by using IEF. IEF has been applied to BF subtyping, revealing the existence of two subtypes in the $\mathrm{BF}^{*} \mathrm{~F}$ allele mainly in Caucasoid populations. We recently developed a new procedure for detecting the FA-FB subtype in the Ba fragment obtained after zymosan treatment (Suzuki et al., 1989). Geserick et al. (1989) reported a Fb1-like variant named FB1 detected in a German family and later they have reported that this variant was different from BF*Fbl in Mongoloid at the VIth Complement Genetics Workshop and Conference (Mainz, F.R.G., 1989). These data thus strongly indicated that BF*Fbl may be characteristic of 
some Mongoloid populations and is the third common allele at BF locus in Mongoloid like BF*F1 and BF*S07 in Caucasoid and Negloid.

When the data of Cambodian and Yonaguni were compared with those of various Mongoloid populations thus far studied (Table 2), the BF alleles distribution of Cambodian is very similar to those of its neighboring populations, Thai and Chinese in Singapore, in Thailand, and in mainland China (Shanghai and Guangzhou), but quite different from Filipinos despite their geographical proximity. In a Japanese population of Yonaguni, the increase of the $\mathrm{BF} * \mathrm{Fbl}$ frequency was accompanied to a larger extent by a decrease of the $B F^{*} \mathrm{~F}$ frequency than by a decrease of the $\mathrm{BF}^{*} \mathrm{~S}$ frequency. This extremely high frequency of $\mathrm{BF}^{*} \mathrm{Fb} 1$ in the island people is ascribable to random genetic drift due to bottleneck effect. Among the Mongoloid populations listed in Table 2, the decrease of the $B F^{*} \mathrm{~F}$ frequency (the $\mathrm{BF}^{*} \mathrm{Fbl}$ frequency was combined to the $\mathrm{BF}^{*} \mathrm{~F}$ frequency for the populations marked with asterisk) and the increase of the $\mathrm{BF}^{*} \mathrm{~S}$ frequency were reciprocally related to the north to south distribution of the populations concerned except for Filipinos of which the $\mathrm{BF}^{*} \mathrm{~F}$ allele frequency were reversely related to their geographical location. This probable cline observed in the BF alleles distribution could be more prominently represented by taking the ratio of $\mathrm{BF}^{*} \mathrm{~F}$ to $\mathrm{BF}^{*} \mathrm{~S}$. This ratio appeared to divide the populations into three groups, high value for Filipinos, medium value for Korean and Japanese, and low value for Chinese, Thai, and Cambodian. Much more data on other Mongoloid populations, however, must be obtained for further discussion.

Among numerous alleles at well-defined polymorphic loci, some are distributed exclusively in one of the three major races but are absent in the other two. As for Mongoloid populations, such specific alleles are typically illustrated by the $\mathrm{Di}^{\mathrm{a}}$ antigen of the Diego blood group (Layrisse et al., 1955), the Gmab3st haplotype of immunoglobulin heavy chain allotypes $(\mathrm{Gm}$, for review see Matsumoto, 1988), the TFDChi allele of transferrin (for review see Kamboh and Ferrell, 1987), a set of rare mutant alleles of vitamin D binding protein (DBP, initially called groupspecific component, Gc, for review see Constans et al., 1985), and so on. The distribution of the rare variants such as TFDChi or DBP variants informs us anthropological relationship between populations, their exchanges, and their migrations (Constans et al., 1985). Based on occurrence or absence of the $\mathrm{BF}{ }^{*} \mathrm{Fbl}$ allele, Mongoloids could be divided into two groups, which findings implied that two core populations might have occurred before the differentiation of Mongoloid into various groups. Such consideration is supported by the vast data on the two polymorphic loci, Gm and DBP. Analytical data on the Gm haplotype distribution among various Mongoloids provides an evidence for the occurrence of two distinct populations among paleo-Mongoloid populations of East Asia in the past (Matsumoto, 1988). In addition, Constans et al. (1985) deduced from the distributions of seven rare variants at DBP locus that considerable differentiation among Mongoloid populations existed, especially between northern and southern ones during the migration to the Americas. 
Table 3. Association of Fb1 with other class III allotypes.

\begin{tabular}{cllll}
\hline ID number & C4A & C4B & C2 & BF \\
\hline 5 & $3,3,2$ & 2,0 & $\mathrm{C}$ & Fb1S \\
8 & 3,0 & 2,1 & $\mathrm{C}$ & Fb1S \\
17 & 4,3 & 2,2 & $\mathrm{C}$ & Fb1S \\
31 & 3,3 & 5,2 & $\mathrm{C}$ & Fb1S \\
37 & 3,0 & 2,1 & $\mathrm{C}$ & Fb1S \\
39 & 3,3 & 1,1 & $\mathrm{C}$ & Fb1S \\
43 & 4,3 & 2,2 & $\mathrm{C}$ & Fb1S \\
44 & $3,3,2$ & 1,0 & $\mathrm{C}$ & Fb1S \\
49 & 3,0 & 2,1 & $\mathrm{C}$ & Fb1S \\
53 & 3,3 & 2,1 & $\mathrm{C}$ & Fb1S \\
60 & 3,3 & 2,2 & $\mathrm{C}$ & Fb1 \\
90 & 3,0 & 4,2 & $\mathrm{C}$ & Fb1S \\
91 & 3,3 & 2,1 & $\mathrm{C}$ & Fb1S \\
99 & 3,0 & 1,0 & $\mathrm{C}$ & Fb1S \\
\hline
\end{tabular}

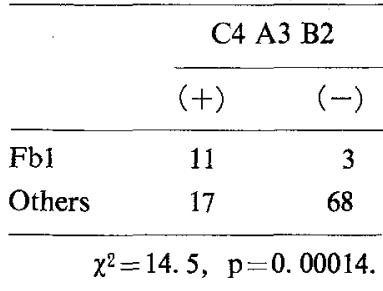

The BF locus is assigned between the locus for $\mathrm{C} 2$ and that for $\mathrm{C} 4 \mathrm{~A}$ within the MHC on chromosome 6 (Carroll et al., 1984), which fact evokes further interest in the distribution of the $\mathrm{Fbl}$ allele. As shown in Table 3, statistical analysis using $2 \times 2$ contingency table confirmed an extremely firm association of $\mathrm{Fb} 1$ phenotypes with $\mathrm{C} 2 * \mathrm{C}$ and $\mathrm{C} 4$ phenotypes with $\mathrm{C} 4 \mathrm{~A} * 3$ and $\mathrm{C} 4 \mathrm{~B} * 2$, thus indicating a firmly linked haplotype, $\mathrm{BF} * \mathrm{Fb} 1, \mathrm{C}^{*} \mathrm{C}, \mathrm{C} 4 \mathrm{~A}^{*} 3$, and $\mathrm{C} 4 \mathrm{~B}^{* 2}$ (Fb1C32). This result showed a good agreement with our previous study (Suzuki et al., 1987a). Although only the other class III types were determined as a Fbl-associated complotype in this and the previous study (Suzuki et al., 1987a), the location of the BF locus within the $\mathrm{MHC}$ region implies that the geographically limited distribution of the $\mathrm{Fb} 1$ allele might be related to the function of the other class I and class II alleles which are linked to the $\mathrm{BF}^{*} \mathrm{Fbl}$ allele. Much better understanding of the Fb1 distribution will be provided by further investigations on northern Mongoloids populations with the information of the MHC class I and class II antigens.

\section{REFERENCES}

Abbal, M., Thomsen, M., Cambon-Thomsen, A., Archambeau, J., Calot, M. and Fatallah, D. 1985. Two subtypes of BfF by isoelectrofocusing: Differential linkage to other HLA markers. Hum. Genet. 69: 181-183.

Alper, C.A., Boenisch, R. and Watson, L. 1972. Genetic polymorphism in human glycine-rich betaglycoprotein. J. Exp. Med. 135: 68-80.

Carroll, M.C., Campbell, R.D., Bentley, D.R. and Porter, R.R. 1984. A molecular map of the human major histocompatibility complex class III region lining complement genes $\mathrm{C} 4, \mathrm{C} 2$ and factor B. Nature 307: 237-241.

Carroll, M.C., Campbell, R.D. and Porter, R.R. 1985. The mapping of 21-hydroxylase genes adjacent to complement component $\mathrm{C} 4$ genes in HLA, the major histocompatibility complex 
in man. Proc. Natl. Acad. Sci. U.S.A. 82: 521-525.

Constans, J., Hazout, R.M., Garruto, D.C., Gajdusek, D.C. and Spees, E.K. 1985. Population distribution of the human vitamin D binding protein: Anthropological considerations. Am. J. Phys. Anthropol. 68: 107-122.

David, V., Fauchet, R., Phengsavath, H., Guenet, L. and Le Gall, J.Y. 1983. Properdin factor B (Bf) polymorphism: Subty ping of SS phenotypes. Hum. Genet. 64: 189-190.

Geserick, G., Patzelt, D., Schroder, H. and Nagai, T. 1983. Isoelectrofocusing in the study of the Bf system: Existence of two common subtypes of the BfF allele. Vox Sang. 44: 178-182.

Geserick, G. and Patzelt, D. 1988. Factor B(BF) subtyping by isoelectric focusing: Methods, nomenclature, genetics and forensic application. Electrophoresis 8: 418-422.

Geserick, G., Rose, M., Martin, W. and Schroder, H. 1989. Detection of a new BF F subtype variant by isoelectric focusing. Exp. Clin. Immunogenet. 6: 156-161.

Greiner, J., Weber, F.J., Mauff, G. and Baur, M. 1980. Genetic polymorphisms of properdin factor $\mathrm{B}(\mathrm{Bf})$, the second component $(\mathrm{C} 2)$, and the fourth component (C4) of complement in leprosy patients and healthy controls from Thailand. Immunobiology 158: 134-138.

Horai, S. 1976. Genetic polymorphism of human serum factor B (Bf) in Japanese. Jpn. J. Human Genet. 21 : 177-186.

Kamboh, M.I. and Ferrell, R.E. 1987. Human transferrin polymorphism. Hum. Hered. 37: 6581.

Layrisse, M., Arends, T. and Dominguez, S.R. 1955. Nuevo group sanguineo encontrado en descendientes de Indios. Acta Medica Venezolana 3: 132-138.

Luo, Z., Du, C., Tokunaga, K. and Omoto, K. 1987. Genetic polymorphism of properdin factor $\mathrm{B}(\mathrm{BF})$ in a Chinese population: Existence of two rare variants. Jpn. J. Human Genet. 32: 33-38.

Matsumoto, H. 1988. Characteristics of Mongoloid and neighboring populations based on the genetic markers of human immunoglobulins. Hum. Genet. 80: 207-218.

Miyano, M., Nanjo, K., Okai, K., Sowa, R., Nomura, Y., Kondo, T., Sanke, T., Kawa, A., Miyamura, K., Aiyathurai, E., Ferunando, R. and Vichayanrat, A. 1986. Properdin factor B frequencies in four Asian populations. Hum. Hered. 36: 129-131.

Müller-Eberhard, H.J. 1988. Molecular organization and function of the complement system. Annu. Rev. Biochem. 57: 321-347.

Nagai, T., Nagai, T. and Ikeda, T. 1986. Isoelectrofocusing in the study of the BfF system: Existence of two common subtypes of the BfF allele in a Japanese population. Forensic Sci. Int. 30: 79-82.

Nakamura, S., Ohue, O. and Abe, K. 1987. A new BF F variant by polyacrylamide gel isoelectric focusing. Hum. Genet. 77: 295-296.

Nishimukai, H. 1982. Studies on genetic polymorphisms of C3 and factor B (Bf) in Japanese. J. Kyoto Pref. Univ. Med. 91 : 1177-1202.

Nishimukai, H., Nakanishi, I., Kitamura, H. and Tamaki, Y. 1988. Factor B subtypes in Japanese patients with IgA nephropathy and with idiopathic membranous nephropathy. Exp. Clin. Immunogenet. 5: 196-202.

O'Neill, G.J., Yang, S.Y. and Dupont, B. 1978. Two HLA-linked loci controlling the fourth component of human complement. Proc. Natl. Acad. Sci. U.S.A. 75: 5165-5169.

Park, K.S., Tokunaga, K. and Omoto, K. 1985. Genetic polymorphisms of complement components $\mathrm{BF}$ and $\mathrm{C} 2$ in Korean: Population and association studies. Jpn. J. Human Genet. 30: $9-14$.

Raum, D., Surgenor, T., Awdeh, Z., Marcus, M., Blumenthal, M., Yunis, E.J. and Alper, C.A. 1984. An unusual "Morphologic" variant of BF S. Am. J. Hum. Genet. 36: 346-351.

Segurado, O.G. and Arnaiz-Villena, A. 1989. Two BF F subtypes, but no BF S, BF F1 or BF S07 subdivision, are found by isoelectric focusing. Vox Sang. 56: 117-121.

Sim, E. and Cross, J. 1986. Phenotyping of human complement protein C4, a class III HLA an- 
tigen. Biochem. J. 239: 762-767.

Suzuki, K., Matsumoto, H., Matsuo, Y., Shoda, K., Iwata, M. and O'Neill, G.J. 1986. Genetic polymorphisms of human complement components in Japanese and their application to parentage testing. In Advances in Forensic Haemogenetics 1. Brinkman, B. and Henningsen, K., eds., Springer-Verlag, Berlin and Heidelberg, pp. 80-84.

Suzuki, K., Harumoto, T., Ito, S. and Matsumoto, H. 1987a. Subtyping of factor B by agarose gel electrophoresis. Electrophoresis 8: 481-485.

Suzuki, K., Charoenwongse, P., Lingao, A.L., Contractor, N.M., Matsushita, S., Sasazuki, T. and Matsumoto, H. 1987b. Factor B polymorphism in four Asian populations: Electrophoretic characterization of a subtype of " $F$ " and of new variants in the Chinese. Electrophoresis 8: 486-489.

Suzuki, K., Ito, S., Tamura, A., Fujita, K. and Matsumoto, H. 1989. Hereditary subtypic patterns detected in the $\mathrm{Ba}$ fragment of complement factor B: Occurrence of four common alleles in Japanese. (submitted to Electrophoresis)

Teng, Y.S. and Tan, S.G. 1982. Subtyping of properdin factor B (Bf) by isoelectrofocusing. Hum. Hered. 32: 362-366.

Tokunaga, K., Araki, C., Juji, T. and Omoto, K. 1982. Polymorphism of properdin factor B in Japanese. Description of a rare variant and data of association with HLA and C2. Hum. Genet. 60: 42-45.

Weidinger, S., Schwarzfischer, F., Burgemeister, T. and Cleve, H. 1984. Two new BfS subtypes revealed by isoelectric focusing and immunofixation. Hum. Genet. 68: 90-92.

White, P.C., Grossberger, D., Onufer, B.J., Chaplin, D.D. and New, M.I. 1985. Two genes encoding steroid 21-hydroxylase and located near the genes encoding the fourth component of complement in man. Proc. Natl. Acad. Sci. U.S.A. 82: 1089-1093.

Zhao, T. 1983. Genetic polymorphisms of $\mathrm{C} 3$ and Bf in the Chinese population. Hum. Hered. 33: $36-38$. 